\title{
GROWTH RESPONSE OF ANTARCTIC SNOW MICROALGAE CULTURES BELONGING TO THE CHLAMYDOMONADACEAE FAMILY TO EFFECTS OF TEMPERATURE, IRRADIANCE AND SUPPORTING MEDIA
}

\author{
RESPUESTA EN CRECIMIENTO DE CULTIVOS DE MICROALGAS DE LAS NIEVES \\ ANTÁRTICAS QUE PERTENECEN A LA FAMILIA CHLAMYDOMONADACEAE \\ A EFECTOS DE TEMPERATURA, IRRADIACIÓN Y MEDIOS DE SOPORTE
}

Pedro Cid-Agüero', Pamela Cárdenas O. ${ }^{2} \&$ Juan Moreno D. ${ }^{2}$

Snow microalgae are a group of freshwater extremophilic organisms that represent several cryophilic (or cold-loving) algae and cyanobacteria that grow on snow and ice during alpine and polar summers (Kawecka 1978). Visible algal blooms in these regions are referred to as red snow or green snow. Despite their diversity, snow algae share their main property: Their optimum growth temperatures are generally around $0{ }^{\circ} \mathrm{C}$ (Teoh et al. 2004). To adapt to this harsh environment, they developed a number of adaptive features, which include biosynthesis of pigments (Fong et al. 2001), polyols (Arnold et al. 2003, Leya et al. 2009), sugars (Arnold et al. 2003), lipids, and spore formation (Pocock et al. 2011, Zang et al. 2003). The spores, which withstand subzero temperatures in winter, usually have large amounts of lipid reserves, polyols and sugars (Rezanka et al. 2008). Microalgae have, therefore, been able to adapt to extreme conditions of light intensity, temperature, $\mathrm{CO}_{2}$ or nutrient availability, which have shaped their photosynthetic apparatus. Oxygenic photosynthesis is a highly integrated bio- energetic process which supplies energy for growth in photoautotrophic organisms (Peltier et al. 2010). Optimal performance of photosynthesis requires a perfect tuning between reactions of light capture and conversion (into reducing and phosphorylating powers) and metabolic reactions involved in the utilization of energy. Light also has a considerable influence on the physiology of snow algae (Carvalho et al. 2009; Raymond 2009). Despite the fact that snow has a high albedo, light intensities in the upper layer of a snowfield are considerably elevated in comparison, for example, with uncovered permafrost soil. Because of the refraction of light, photon intensities within snow can reach values two or three times higher than that of the incidence of photon irradiance on the snow surface (Gorton et al. 2001). The protective role of polyunsaturated fatty acids against the damaging effect of high light intensity and UV radiation, especially at low temperature, might help the organisms to survive and adapt to extreme environments (Becker et al. 2010, Guschina et al. 2006). The production of polyunsaturated fatty acids

1 Dirección de Programas Antárticos, Universidad de Magallanes, Punta Arenas, Chile. pedro.cid@umag.cl.

2 Departamento de Ingeniería Química, Universidad de Magallanes, Punta Arenas, Chile. 
under stress conditions could make them valuable production strains in biotechnology. Although the existence of snow microalgae has been known for some time, their appropriate conditions for laboratory cultures, chemical characteristics and potential use in biotechnology have not yet been fully explored (Mata et al. 2009, Huang 2010).

In the present study, physical parameters for optimal growth in captivity of fresh water green snow microalgae that belong to the family Chlamydomonadaceae where measured and are reported herein. Such species were collected near the Chilean Antarctic Base, Bernardo O'Higgins (63 $19^{\prime}$ S 57 $54^{\prime} \mathrm{W}$ ). The microalgae samples were collected in January, from the snow surface, within 1 or two centimeters deep, where they were at aprox. $-1^{\circ} \mathrm{C}$ of temperature, and a $\mathrm{pH}=7.88$ in their natural medium. These samples were kept refrigerated at $-20^{\circ} \mathrm{C}$ at all times. Later in the laboratory the microalgae samples were transferred to a culture media, at pH 7.5, a medium recommended by J. Cuello (pers. comm., Department of Agricultural and Biosystems Engineering, University of Arizona), into sterilized test tubes that were kept into a thermo-regulated bath. Since, the lipid content of microalgae vary in accordance with culture conditions, the reproduction of these algae, depending on factors such as light, temperature and supporting media was performed. The cultures were maintained in a controlled-environment incubator at temperatures ranging from 4 to $20^{\circ} \mathrm{C}$, with a light regime of 12:12 h light-dark cycles. Separate batches of cultures on triplicate were grown at each temperature. The temperature range used for this study was based on the studies of Teoh et al. (2004). The brightness intensities used were 250, 297 and 317 Lux, and the supporting media selected were: agar, white stones and sand. We selected these last parameters in our study, to explore the influence of ice as the supporting medium for the microalgae in their natural environment, in this case beeing replaced by other similar natural media that can be easily included in a potential large-scale production system without further modifications. Data were collected by measuring the weight of the algae biomass once a day under different temperature, irradiance and supporting media conditions, by changing these parameters one at the time.

The best temperature for this algae growth was $12^{\circ} \mathrm{C}$ (Fig. 1), but also including other conditions: brightness of 250 Lux and without solid supporting medium. According to the classification by Hoham (1975) snow algae are those that do not grow at temperatures above $10^{\circ} \mathrm{C}$ and have optimum growth at lower temperatures; however, our results showed an optimal temperature a little higher, probably due to a combination of factors related to the general condition given for the culture. When the growing data were used in correlations to be compared to growth kinetic models, we found that the tendencies at 4 and $20^{\circ} \mathrm{C}$ fits better to logarithmic curves and the curve for $12^{\circ} \mathrm{C}$ follow the Monod type of kinetics. Certainly, more detailed experiments are needed to properly describe the growth kinetics of these species.

Once the optimum growth temperature was defined, a series of tests for cultures exposition at

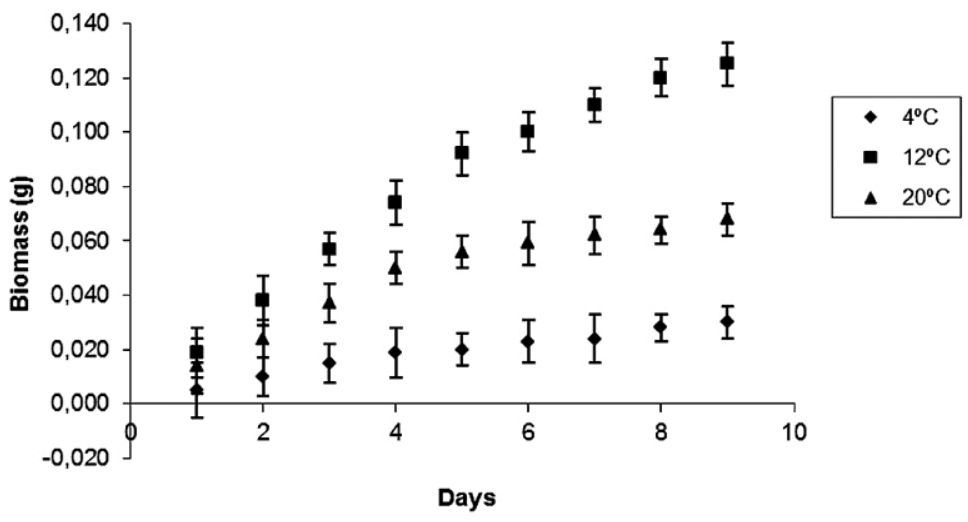

Fig. 1. Average growth rate of microalgae under different temperature conditions. Initial sample mass was 1 gram. Error bars represent fluctuations in biomass among trials. 
Table 1. Average growth of Chlamydomonas sp. at different illumination after 10 days of light exposure. Percent error is given by dispersion among trials.

Light (Lux)

250297317

Culture Growth (\%)

$608 \pm 12452 \pm 8427 \pm 20$

different light intensities was done. Light intensities were adjusted by using combinations of light bulbs and monitored by a luxometer. The results are summarized in Table 1 . The data represents the gain in biomass after 10 days, indicating that the microalgae will grow better in a moderated light intensity environment, which is consistent with previous reports for another species (Alric 2010; Raymond et al. 2009; Ackley \& Sullivan 1994; Lancelot et al. 1993). On the other hand McMinn et al. (2007) reported photoadaptive index values (PAR) of $19-44 \mu \mathrm{mol}$ photons $\mathrm{m}^{-2} \mathrm{~s}^{-1}$ in East Antarctic sea ice algae sampled in spring season. At light levels below the photoadaptive index, growth is light-limited. If we consider the sun light visible normal spectrum, then we are below such limits in our results, but there is not enough information to solve this disparity, since in our experiments, the growth was strongly inhibited by higher than 250 lux (aprox. 4.5 PAR) illuminance.

A third parameter explored was the supporting media. In their natural habitat, the snow algae grow in the surface of ice crystals, therefore, in this experiment three different solid media: agar, white stones and sand, were added to the culture in an attempt to see the influence of solid, porous, and reflective media in the growth rate of snow microalgae. The results clearly show that the best supporting media among the three of them are white stones (see Table 2), which provided a growing medium closer in characteristics to their natural environment.

In conclusion, we were able for the first time to successfully cultivate fresh water green snow mi-

Table 2: Average percentage of growth culture of Chlamydomonas sp. in different supporting media after ten days of being cultivated. Percent error is given by dispersion among trials.

\begin{tabular}{lc}
\hline Supporting Media & Culture Growth (\%) \\
\hline White stones & $1,487 \pm 30$ \\
Sand & $639 \pm 21$ \\
Agar & $1,063 \pm 25$ \\
Without medium & $458 \pm 18$
\end{tabular}

croalgae from the Antarctic Peninsula in captivity. According to our results, the best conditions for this algae growth are: the temperature must be $12^{\circ} \mathrm{C}$, a brightness of 250 Lux and the use of white stones as the supporting medium. These conditions produced a higher amount of biomass in a reasonably short period of time. These results are encouraging for extending the studies for possible biotechnological application of these microalgae.

\section{ACKNOWLEDGMENT}

This study was partially funded by a research grant from the Chilean Antarctic Institute (INACH). Logistic and field assistance of the staff of Chilean Army Antarctic Department (DAE) and O'Higgins Antarctic Base is deeply appreciated. The authors would like to thanks Dr. Joel Cuello for his kind advice as well as technical recommendations and Dr. J.C. Uribe for his insights in microalgae technology.

\section{LITERATURE CITED}

Ackley, S.F. \& C.W. Sullivan 1994. Physical controls on the development and characteristics of Antarctic sea ice biological communities-a review and synthesis. Deep Sea Research Part I- Oceanographic Research Paper, 41:1583-1604

Alric, J. 2010. Cyclic electron flow around photosystem I in unicellular green Algae, Photosynthesis Research, 106:47-56

Becker, S., Graeve M. \& K. Bischof 2010. Photosynthesis and lipid composition of the Antarctic endemic rhodophyte Palmaria decipiens: efects of changing light and temperature levels. Polar Biology, 33:945-955

Carvalho, A.P., Monteiro C.M. \& F. X. Malcata 2009. Simultaneous effect of irradiance and temperature on biochemical composition of the microalga Pavlova lutheri. Journal of Applied Phycology, 21:(5) 543-552

Fong, N. J. C., Burgess M. L., Barrow K. D. \& D. R. Glenn 2001. Carotenoid accumulation in the psychrotrophic bacterium Arthrobacter agilis in response to thermal and salt stress Applied Microbiology Biotechnology, 56:750-756

Gorton, H.L., Williams W.E. \& T.C. Vogelmann 2001. The light environment and cellular 
optics of the snow alga Chlamydomonas nivalis (Bauer) Wille. Photochemistry and Photobiology, 73:611- 620

Guschina, I.A. \& J.L. Harwood 2006 Lipids and lipid metabolism in eukaryotic algae. Progress in Lipid Research, 45:160-186

Hoham, R.W. 1975. Optimum temperatures and temperature ranges for growth of snow algae. Arctic Alpine Research, 7: 13-24

Huang, G. 2010. Biodiesel production by microalgal biotechnology. Applied Energy Reviews, 87:38-46

Kawecka, B. \& Drake 1978. Biology and Ecology of Snow Algae. Acta Hidrobiológica, 20: 111-116

Lancelot, C., Mathot S., Veth C. \& H. de Baar 1993. Factors controlling phytoplankton ice-edge blooms in the marginal ice-zone of the northwestern Weddell Sea during sea ice retreat 1988: field observations and mathematical modelling. Polar Biology, 13:377- 387

Leya, T., Rahn A., Lutz C. \& D. Remias 2009. Response of arctic snow and permafrost algae to high light and nitrogen stress by changes in pigment compositionand applied aspects for biotechnology. FEMS Microbiology Ecology, 67:432-443

Mata, T.M., Martins A.A. \& N.S. Caetano 2010. Microalgae for biodiesel production and other applications: A review. Renewable and Sustainable Energy Reviews, 14:217-232

McMinn, A., Ryan K.G., Ralph P.J. \& A. Pankowski 2007. Spring sea ice photosynthesis, primary productivity and biomass distribution in eastern Antarctica, 2002-2004. Marine Biology, 151:985-995
Peltier, G., Tolleter D., Billon E. \& L. Cournac 2010. Auxiliary electron transport pathways in chloroplasts of microalgae. Photosynthesis Research, 106:19-31

Pocock, T., Vetterli A. \& S. Falk 2011. Evidence for phenotypic plasticity in the Antarctic extremophile Chlamydomonas raudensis Ettl. UWO 241. Journal of Experimental Botany, 62 (3):1169-1177

Raymond, B., Meiners K., Fowler C. W., Pasquer B., Williams G. D. \& S. Nicol 2009. Cumulative solar irradiance and potential large-scale sea ice algae distribution off East Antarctica (30E-150E). Polar Biology, 32: 443-452

Rezanka, T., Nedbalova L. \& K. Sigler 2008. Unusual medium-chain polyunsaturated fatty acids from the snow alga Chloromonas brevispina. Microbiological Research, 163: 373-379

Teoh, M.L., Chu W. L., Marchant H. \& S.M. Phang 2004. Influence of culture temperature on the growth, biochemical composition and fatty acid profiles of six Antarctic microalgae, Australia. Journal of Applied Phycology, 16:421-430

Whitelam, G.C. \& G.A. Codd 1986. Damaging effects of light on microorganisms. In: Herbert, R. A. \& G. A. Codd (eds.). Microbes in extreme environments. London: Academic Press. p. 129 - 69

Zhang Q., Gradinger R. \& Q.S. Zhou 2003. Competition within the marine microalgae over the polar dark period in the Greenland Sea of high Arctic. Acta Oceanologica Sinica, 22 (2):233-242 